\title{
The Trouble with HARRIS (Hypersensitivity and Allergic Reactions Related to Iatrogenic Substances)
}

\section{Gianfranco Calogiuri*}

Department of Pneumology and Allergy, Civil Hospital Ninetto Melli, San Pietro Vernotico, Brindisi, Italy

*Corresponding author: Gianfranco Calogiuri, Department of Pneumology and Allergy, Civil Hospital Ninetto Melli, San Pietro Vernotico, Brindisi, Italy, E-mail: gf.calogiuri@libero.it

Received date: April 12, 2016; Accepted date: April 16, 2016; Published date: April 19, 2016

Copyright: ( 2016 Calogiuri G. This is an open-access article distributed under the terms of the Creative Commons Attribution License, which permits unrestricted use, distribution, and reproduction in any medium, provided the original author and source are credited

\section{Editorial}

In an old movie, "The trouble with Harry" (Paramount Pictures, 1955), a little masterpiece of black comedy directed by a great Alfred Hitchcock at his best, the inhabitants of a small village in Vermont have to manage the dead body of a man, named Harry, found on a hillside. Three of the main characters in the movie each believe that he or she is the person who killed Harry incidentally and everybody tries to hide Harry's corpse, who becomes literally a "walking dead", hauled and hidden, far away from the local policeman attention, for all the movie along. So, all the main characters have to bury the body and then dig it up again several times for different reasons, until the village's doctor establishes at last, that Harry died of natural causes.

Actually, drug allergy and drug hypersensitivity are treated by most of the doctors as Harry's dead body: they try to hide or to minimize the onset of an allergic reaction to a drug they have prescribed or administered.

Such a behavior has many causes. Firstly, the guilt to have induced a damage to the patient, so violating the first rule of ars medica: primum, non nocere.

Then the fear of legal consequences, especially in United States, where specialized lawyers, through specific Internet platforms, propose patients to claim rewards and suggest them to contact an "experienced Stevens-Johnson syndrome attorney (sic!) to discuss their situation, evaluate the legal options available and determine the types of StevensJohnson Syndrome damages for which they may be entitled [1] and that site is not one of the most aggressive even.

It is necessary to remind drug hypersensitivity reactions are unusual, complicated and, above all, poorly predictable diseases related to the assumption of a drug at a dosage normally tolerated by most of patients.

Then drug hypersensitivity shows a wide range of clinical presentations and that represents another trouble, because skin involvement is really dangerous as in Steven Johnson syndrome or in Lyell syndrome, but their clinical presentation is obvious, so allowing to alert doctors about the onset of the reaction. Sometimes, other organs are involved in a more silent way as in drug induced hepatitis or nephropathy or in a dramatic way as in drug induced aseptic meningitis and the delayed consequent diagnosis may be highly harmful and invaliding to the patient.

Consequently, many doctors regret not to have much more information about a patient's "drug hypersensitivity" when they are collecting his clinical history, so they are forced to "dig" any circumstance regarding the onset of a previous adverse drug reaction up from patient's memory. Unfortunately, patient memory is not always very helpful to them, as confirmed by the discrepancy between the true penicillin allergy incidence and the presumed self-reported penicillin allergy [2].

For that reason, European Network for Drug Allergy (ENDA) group has elaborated and developed a drug allergy passport, where the previous drug hypersensitivity of patients is documented with description of type of reaction, severity, the name of culprit drugs and other useful informations patient should carry when he is abroad or out of home [3].

Another trouble with HARRIS is that many factors play a role: factors related to the drug as route of administration, toxicity, how long the medication has been assumed and/or interrupted previously, its water or fat solubility and its binding protein ability, while other factors are connected to the patient status: atopy, being a slow acetylator, certain Human Leucocyte Antigen (HLA) haplotypes, influencing drug presentation as antigen to the immune system and other undervalued factors as the previous exposition to cross-reactive substances, sometimes apparently innocent as a henna tattoo [4]. There is no "gold standard" therapy for drug allergy, so diagnosis, treatment and prevention are entrusted with the good will of the operator.

Yet, it is necessary to consider the "ideological" face of the problem: in drug allergy, the differences in the clinical approach to patients and diseases between American and European doctors are more evident, starting from books published on the matter. The American "Drug allergy and protocols for management of drug allergies" by Grammer and Greenberger, has got 52 pages whereas "Drug Hypersensitivity" by the Austrian Pichler has got 427 pages, about the same pages of the Australian "Drug Allergy" by Baldo and Pham (although, Americans make up for the gap, thanks to practical and useful manuals as the Clinics of North America).

The American approach is highly pragmatical, direct and quick and the attention is focused mainly on penicillin allergy and aspirin induced asthma, as the European approach is more careful and investigative, eager to understand the pathomechanisms of drug hypersensitivity and it includes any kind of drugs. Apparently, it looked like a waste of time, but such an approach has generated the publication of many innovative articles in the field of allergy and dermatology on the last decades, derived from European immunological studies, as the identification of four subgroups of cellmediated hypersensitivity linking the clinical presentation of skin eruptions to specific drug related T cell-subsets and particular cytokine inflammatory patterns proposed by Pichler [5] or the classification of corticosteroid contact hypersensitivity in four groups related to their different stereo chemical structure suggested by Coopman and Goossens [6]. Their classification can be used successfully in drug 
induced severe cutaneous reactions as acute generalized exanthematous pustulosis due to glucocorticoids [7].

The Asians prefer the European approach because of the high rates of incidence and prevalence of drug induced severe cutaneous adverse reactions in their populations, linked to pharmacogenetic reasons [8].

Nevertheless, Americans firstly have noticed that drug allergy/ hypersensitivity represents the first cause to claim an allergistimmunologist consultation [9].

The necessity to collect more answers and competences on drug allergy is so deep that, for instance, even cardiologists have been compelled to investigate clopidogrel hypersensitivity by themselves and their study has not been published on an allergy journal but on a cardiology journal [10], so demonstrating the magnitude of the problem.

Paradoxically, that aspect of allergy and clinical immunology discipline, where most of other doctors and specialists require allergist opinion and competence, is undervalued by most of the same allergists, because the investigations for drug allergy result often frustrating.

Firstly, for most of the drugs, skin tests are not standardized and actually there are not useful and certain in vitro tests for drug allergy, except identification of specific IgE towards few drugs, as lymphocyte transformation test (LLT) and basophil activation test (BAT) are still experimental and performed by few laboratories in University centers only. No diagnostic biomarkers of activation have been surely identified for $\mathrm{T}$ cells mediated drug hypersensitivity [11], no animal models are available for many of these diseases and no accepted test procedures exist to confirm surely the involvement of a drug in these adverse effects.

Despite the big steps on this way, the pathophysiological mechanisms of most of these diseases are not well understood and the causal relationship between drug intake and the manifestation of a hypersensitivity reaction as, for instance, the Guillain-Barre' syndrome associated to zimeldine assumption [12], remains an enigma.

In this context, the lack of interest by the industry and funding agencies (there are no grants or doctorates on drug hypersensitivity) is surprising and probably it does not encourage researchers to study more carefully allergic reactions to drugs.

For a company, it is a great financial loss to remove a drug from the market after spending millions in development, because it provokes severe hypersensitivity reactions as it happened for valdecoxib [13]. That episode demostrates pharmaceutical industries are wrong not to invest on drug hypersensitivity. A study to evaluate the tolerability of new drugs as febuxostat in allopurinol sensitive patients or the use of fondaparinux in subjects with allergy to hepainoids, not restricted to little cohorts of patients $[14,15]$, is not only helpful to doctors and patients to confirm the security profile of these drugs as alternative molecules, but it could be a good marketing tool to increase their prescriptions, or alternatively to prevent a further valdecoxib experience.

On the contrary, in these years, researchers have tried to develop position papers and an international meeting to increase the exchange of informations among the fews of them interested to that argument, so to optimize their knowledge's. The European Academy Allergy Clinical Immunology (EAACI) organizes the Drug Hypersensitivity Meeting in different European cities since 2002 and it has established some grants for studies on drug allergy, too.
Moreover, even in USA, "things change" (Columbia Tristar, 1988, by David Mamet) and Americans have also realized drug hypersensitivity is a true iatrogenic disease with multiple faces and it is a big trouble of Western societies, where there is a high rate of hypermedicalization, causing increased costs of hospitalization and harmful outcome for patients [16]. In 2013, the Division of Allergy, Immunology, and Transplantation of the National Institute of Allergy and Infectious Diseases sponsored a workshop on drug allergy, inviting most of the eminent international experts in the field of drug allergy covering different backgrounds and specialties (allergy, immunology, infectious diseases, dermatology, clinical pharmacology, and pharmacogenomics) to discuss the current state of drug allergy research and to expand and redirect the trends of future investigations and researches on the argument [17]. So, it will be wishful Americans invade the field of drug allergy with their competences, enthusiasm and means, not only limited to anedoctal case report or experimental drug desensitization protocol in a single patient.

\section{References}

1. See at: http://injury-law.freeadvice.com/injury-law/drug-toxic_chemicals/ stevens-johnson-syndrome-lawsuit-damages.htm

2. Macy E, Schatz M, Lin C, Poon KY (2009) The falling rate of positive penicillin skin tests from 1995 to 2007. Perm J 13: 12-18.

3. Brockow K, Aberer W, Atanaskovic-Markovic M, Bavbek S, Bircher A, et al. (2016) Drug allergy passport and other documentation for patients with drug hypersensitivity - An ENDA/EAACI Drug Allergy Interest Group Position Paper. Allergy.

4. Calogiuri GF, Muratore L, Casto AM, Romita P, Castagnaro A,et al. (2014) Delayed-type hypersensitivity to henna tattoo components: 2 case reports. Austin J Allergy 1: 1-3.

5. Pichler WJ (2003) Delayed drug hypersensitivity reactions. Ann Intern Med 139: 683-693.

6. Coopman S, Degreef H, Dooms-Goossens A (1989) Identification of cross-reaction patterns in allergic contact dermatitis from topical corticosteroids. Br J Dermatol 121: 27-34.

7. Buettiker U, Keller M, Pichler WJ, Braathen LR, Yawalkar N (2006) Oral prednisolone induced acute generalized exanthematous pustulosis due to corticosteroids of group A confirmed by epicutaneous testing and lymphocyte transformation tests. Dermatology 213: 40-43.

8. Thong BY (2013) Stevens-Johnson syndrome / toxic epidermal necrolysis: an Asia-Pacific perspective. Asia Pac Allergy 3: 215-223.

9. England RW, Ho TC, Napoli DC, Quinn JM (2003) Inpatient consultation of allergy/immunology in a tertiary care setting. Ann Allergy Asthma Immunol 90: 393-397.

10. Cheema AN, Mohammad A, Hong T, Jakubovic HR, Parmar GS, et al. (2011) Characterization of clopidogrel hypersensitivity reactions and management with oral steroids without clopidogrel discontinuation. J Am Coll Cardiol 58: 1445-1454.

11. Beeler A, Zaccaria L, Kawabata T, Gerber BO, Pichler WJ (2008) CD69 upregulation on $\mathrm{T}$ cells as an in vitro marker for delayed-type drug hypersensitivity. Allergy 63: 181-188.

12. Fagius J, Osterman PO, Sidén A, Wiholm BE (1985) Guillain-Barré syndrome following zimeldine treatment. J Neurol Neurosurg Psychiatry 48: $65-69$.

13. U.S. Food and Drug Administration. Information for healthcare professionals: valdecoxib (marketed as Bextra) 2005.

14. Chohan S (2011) Safety and efficacy of febuxostat treatment in subjects with gout and severe allopurinol adverse reactions. J Rheumatol 38: 1957-1959.

15. Warkentin TE, Pai M, Sheppard JI, Schulman S, Spyropoulos AC, et al. (2011) Fondaparinux treatment of acute heparin-induced thrombocytopenia confirmed by the serotonin-release assay: a 30-month, 16-patient case series. J Thromb Haemost 9: 2389-2396. 
Citation: Calogiuri G (2016) The Trouble with HARRIS (Hypersensitivity and Allergic Reactions Related to latrogenic Substances). J Allergy Ther 7: e112. doi:10.4172/2155-6121.1000e112

Page 3 of 3

16. Sheridan RL, Schulz JT, Ryan CM, Schnitzer JJ, Lawlor D, et al. (2002) Long-term consequences of toxic epidermal necrolysis in children. Pediatrics 109: 74-78.
17. Wheatley LM, Plaut M, Schwaninger JM, Banerji A, Castells M, et al. (2015) Report from the National Institute of Allergy and Infectious Diseases workshop on drug allergy. J Allergy Clin Immunol 136: 262-271. 